\title{
Teaching Design for All Through Empathic Modeling: A Case Study in Tallinn University
}

\author{
Vladimir Tomberg and Mart Laanpere \\ Institute of Informatics, Tallinn University, Estonia \\ \{vtomberg, martl\} @tlu.ee
}

\begin{abstract}
The goal of the paper is to illustrate best practices that can be used in Design for All courses. We implemented the empathic modeling approach in HCI study programme by letting the students simulate users with disabilities in the physical settings in order to increase their understanding of Design for All in their work as HCI designers. The data was collected from students with online questionnaire and open reflections after the course.
\end{abstract}

Keywords: Accessibility, Design for All, Empathy, Empathic Modeling, Teaching DfA.

\section{Introduction}

The Pillar VI in European Union's strategy 'Digital Agenda for Europe' sets ambitious goals towards enhancing digital literacy, skills and inclusion [1]. In the context of HCI, the latter of these goals is being targeted by the widening movement called Design for All (DfA). Similar initiatives emerge in other parts of the world, sometimes under other labels like Universal or Inclusive Design. The most notable achievements of DfA community are projects like DfA@eInclusion1 and guidelines for DfA curricula on bachelor and master level in EU and US [2-4].

Considering actions 64 "Ensure the accessibility of public sector websites" and 65 "Helping disabled people to access content" of Pillar VI, the dissemination of knowledge about DfA among software developers seems as especially important. However, no clear guidelines are given to software designers as to how to design for all in practice [5]. There is still no consensus on which phases of software manufacturing cycle should DfA principles to be applied and who should be responsible for the application. As a consequence, there is another threat. Many accessibility principles can be implemented and validated on the level of code. While such low-level implementation is formally valid, it cannot guarantee universal accessibility if DfA principles were not used in the initial phases of design. By focusing mainly on the code, the developers often have no chance to reveal empathy towards potential end-users with different abilities, which is an important prerequisite for inclusive software design.

\footnotetext{
${ }^{1}$ http: / /www.dfaei.org/
} 
Our case study demonstrates how these issues can be addressed by applying empathic modeling as a pedagogical approach in teaching DfA as part of a software engineering curriculum.

We validated our assumptions in context of DfA course for HCI master students that took a place in Tallinn University during the first semester of 2013.

\section{Reasons for Design for All}

Since the 1960s the world population achieved 7 billion, as fertility has exceeded mortality by 200 percent [6]. One noticeable indicator of population ageing is Potential Support Ratio (PSR) - the number of persons aged 15 to 64 per every person aged 65 or older. According to Haux et al [7] only 2 persons will be aged under 64 for each one older person in 2050 in Europe (Table 1).

Table 1.

\begin{tabular}{ccc}
\hline Year & PSR worldwide & PSR for Europe \\
\hline 1950 & 12 & 8 \\
\hline 2000 & 9 & 5 \\
\hline 2050 & 4 & 2 \\
\hline
\end{tabular}

These values prompt us that it will be hard for the old people in future to expect the same level of support that they have today. Also it is clear that the number of older people in the population and the length of time these people remain dependent on social security and healthcare systems after retirement will be significantly increased [8]. By considering these circumstances a focus of research nowadays shifts from the life expectancy to the quality of life and to ways of living in the old age. Biologists and health researchers try to reveal the ways for improving personal health of the old people to support their active personal and professional life.

However it is clear that improvement of the personal health only is not enough for supporting active lifestyles. Such personal abilities as vision, hearing, thinking, communication, reach and stretch, dexterity, and locomotion have tendency to degrade with age. This demands from people to leave their habitual jobs and reduce their activities. In addition to improvement of personal health, there is a clear demand for supporting active living by environmental conditions. For example, Ambient Assisted Living (AAL) [9] addresses the needs of the ageing population, and aims to reduce innovation barriers of forthcoming promising markets, and lower future social security costs. In the context of aging societies, ambient intelligence has focused on providing assistive solutions for elders at risk of losing their independence [10]. The understanding of AAL is that it aims:

- to extend the time people can live in their preferred environment by increasing their autonomy, self-confidence and mobility;

- to support maintaining health and functional capability of the elderly individuals, to promote a better and healthier lifestyle for individuals at risk; 
- to enhance the security, to prevent social isolation and to support maintaining the multifunctional network around the individual;

- to support careers, families and care organizations;

- to increase the efficiency and productivity of used resources in the ageing societies [11].

Only the second of the aims mentioned above directly addresses personal health, while other four more related to design and development of near and global environments. For achieving such aims Design for All principles should be widely adopted in practice. These principles are intended to ensure accessibility at design time and to meet the individual needs, abilities and preferences of the user population at large, including disabled and elderly people [12]. A core methodology of design for All is User Centered Design, which enables developers to focus on the users as the heart of the design process, and also involves disabled people as an integral part of such design [13].

By following these ideas we presume that software developers should to be involved in co-design process together with the interaction designers and potential end-users. The software designers and engineers should at first be aware about the needs of society for inclusion and different abilities of potential end-users. By being aware of users with different needs the designers should avoid common practice of designing products for 'average' users [14]. They should know how to learn about their potential audience and they should practice empathy to the end-users during the process of development. Finally, developers should have an ability to transfer gathered knowledge about users to the digital realm. Kouprie and Visser ask: how to design a communication product for elderly people, with a design team consisting of marketers, engineers, product designers, usability professionals, etc., if none of them belongs to the user group himself? [15]

To help developers reveal some hidden and not obvious needs of users that can be used in design decisions the emphatic modeling method is used.

\section{$3 \quad$ Emphatic Modeling}

According to Decety \& Jackson an experience of empathy is a "natural ability to understand the emotions and feelings of others, whether one actually witnessed his or her situation, perceived it from a photograph, read about it in fiction book, or merely imagined it" [16]. By citing Reik [17], Decety \& Jackson described the following four processes that are involved in empathy:

- Identification: focusing one's own attention to another and allowing oneself to become absorbed in contemplation of that person;

- Incorporation: making the other's experience one's own via internalizing the other;

- Reverberation: experiencing the other's experience while attending to one's own cognitive and affective associations to that experience; 
- Detachment: moving back from the merged inner relationship to a position of separate identity, which permits a response to be made that reflects both understanding of others as well as separateness from them [16].

A similar model that consists of the same amount of properties but stresses them in a slightly different way was proposed by Wiseman:

- See the world as others see it;

- Be nonjudgmental;

- Understand another's feelings;

- Communicate the understanding.

These properties can be considered as useful for designers, who use the usercentered design approach with the aim of identifying user's points of view, abilities and constrains that they may have in interaction with a specific artifact.

Apparently, the goodwill to have empathy without the real experience is not enough to learn about being aged, pregnant or blind. Special activities are required to place the designer "in the shoes" of a person with different abilities. For such kind of activities, a special method of empathic modeling is used.

Torrens defined empathic modeling as "a well-used method through which designers can gain some experience of the constraints of a defined medical condition that manifests itself in a form of impairment" [18]. Nicolle and Maguire describe empathic modeling as the method whereby an individual, using various props and scenarios, is able to simulate the deterioration of physical and perceptual abilities in everyday scenarios [19]. Different empathic tools like wearable and software simulators can be used to restrict the users' capabilities, so that they find it more difficult to see and to move, or to show the effects of vision and hearing impairments on image and audio computer files [20].

Through empathic modeling, the designer aligns with user's emotional aspirations and values, which is critical for effectively providing the basis for product desirability or acceptance [18].

\section{Course Design}

The experimental DfA course was taught at October - November 2013 within the scope of HCI master curricula in Tallinn University. This blended-learning course included 4 biweekly meetings, each lasting for five hours and several homework assignments that had to be reflected in the Personal Learning Environments (blogs) of the students.

In the class lectures, the students learned about historical roots of Inclusive Design, Universal Design and Design for All. They learned why DfA is an important trend today, and how inclusive design approaches are different from traditional design methods. Information about DfA movement and corresponding legislation acts on worldwide and European scales was presented. Related ICT specifications such as W3C Recommendation, WCAG 2.0 and Accessible Rich Internet Applications Suite WAI-ARIA were described. 
The students familiarized themselves with the concept of disability and different types of personal human characteristics such as vision, hearing, thinking, communication, reach and stretch, dexterity, and locomotion. The students learned about differences in the personal abilities between different age groups. After meeting with basic principles of Universal Design [21] such as ergonomically sound, perceptible, cognitively sound, flexible, error-managed (proofed), efficient, stable and predictable, equitable [22], the specific design guidances that address limitations for different abilities were presented and examined with the students with corresponding DfA examples.

The course assignments followed the approach of empathic modeling [19], as students were repeatedly invited to put themselves in the shoes of people with disabilities, both as users of a physical environment (university building) and digital environments. During the course students had to complete three home assignments using their personal learning blog: Observation, Finding the good examples around, and Finding the good HCI examples.

\subsection{Observation}

This assignment was the main empathic task for the students. They had to find a way to a specific room in a building by simulating some form of deterioration. This exercise aimed an empathy experience which should be produced by new uncomfortable conditions for the student in the habitual environment (well known building). The students were able to choose a disability on their own. Examples of chosen disabilities were persons in a wheelchair, with a pushchair, with limited vision, with limited dexterity, with osteoporosis, with broken leg, without arms, and a foreigner, to check navigation facilities. All student documented their ways using photo and video cameras and reported stories about their new experience in their personal learning blogs (Fig. 1).
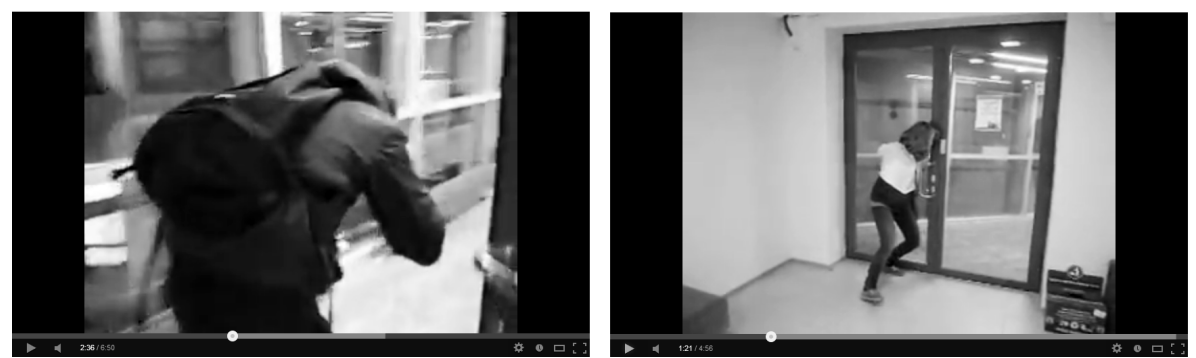

Fig. 1. A student with a handicap in a backpack simulating osteoporosis (left) and a student with tied arms simulating a person without arms (right)

Besides personal reflection the students also had a group work, where they collected all obstacles and design issues they met in the building during implementing task. The obstacles were sorted and prioritized according to level of treat and an amount of people that are affected by each obstacle. On the base of this analysis students proposed several design solutions that may help to avoid problems for people with limited abilities. 


\subsection{Finding the Good Examples Around}

The students had to find, make pictures and describe five examples of physical artifacts around (on a street, in a bus, or in a leaving place). This exercise was implemented after the observation exercise, so students already had an imagination, what kind of design can be hardly accessible by specific people. The aim of this exercise was to train an skill for recognizing real world design issues on the base of experience received during the empathic modeling exercise. The student provided pictures and descriptions of the examples in their personal blogs.

\subsection{Finding the Good HCI Examples}

After two exercises conducted in the outside environment and getting a base knowledge about different types of abilities the students were assigned with a task related to the digital world. In this homework the students had to find and document five examples of DfA principles implemented in the Web sites, software application, or any other type of electronic services. The aim of this exercise was to transfer knowledge about DfA values and principles to the digital realm.

\section{$5 \quad$ Research Design}

After finishing the course the students were asked to reflect upon their learning experience in their blogs and fill in an empathy assessment questionnaire that contained 10 questions with Likert scale. The questionnaire was designed in Limesurvey tool and was provided online on anonymous base. The questionnaire included several general demographic data about participants, one group of questions that measure empathy and one group of questions intended for assessment of results of the course.

There are several studies available on topic of measuring empathy and evaluation of empathy scales [23-25]. The part of questions for the questionnaire was borrowed from Empathy Quotient (EQ) tool that was validated by Lawrence et al and showed High test-retest reliability [23].

Table 2. A subset of items from Empathy Quotient tool to measure general empathy level

\begin{tabular}{l}
\hline \multicolumn{1}{c}{ To what extent do you agree with the following statements - } \\
\hline I really enjoy caring for other people \\
\hline I often find it difficult to judge if something is rude or polite \\
\hline I find it easy to put myself in somebody else's shoes \\
\hline I am good at predicting how someone will feel \\
\hline I am quick to spot when someone in a group is feeling awkward or uncomfortable \\
\hline
\end{tabular}


This comprehensive tool was designed for measuring user empathy in clinical context and was validated in series of four studies examined the reliability and validity of the EQ. While EQ questionnaire is quite big and contains of 60 questions, authors recommend that the different subscales may have clinical applications.

For assessing effect of empathy modeled in real world to understanding needs of people with limited abilities in digital realm we added into questionnaire five specific items relevant for our research focus, these are listed in Table 3.

Table 3. Original Likert-type items added to the survey questionnaire

To what extent do you agree with the following statements -

Understanding the general principles of design for all in physical settings helps a designer to apply them in HCI context

I learned from our exercise with simulation of deterioration something that can be transferred to the context of HCI design

I did not like to play the role of a disabled person during the course assignment

It is important to include such simulation exercises in physical context in the course of universal design for HCI students

Prior to this course I had less empathy towards users with disabilities

We also collected qualitative data by asking students to reflect in their study blogs upon the following open-ended questions:

1. Was the exercise of finding the way in the University building useful for following understanding DfA issues in this HCI examples exercise? How?

2. Was the previous exercise "Good examples of real life DfA artifacts" useful for following understanding DfA issues in this HCI examples exercise? How?

3. From the point of view of DfA, what commons and differences between the physical objects in environmental context and HCI artifacts you can define?

\section{$6 \quad$ Results}

The responses to survey questionnaire were submitted by 16 students, half of them were female. The age distribution of respondents matched the typical one for MA study groups in the Institute: two students belonged to the age group 21-22 years, six students to 23-25, four students to 26-30 and four were older than 30. Only two respondents did not have any work experience in IT industry, the others have been working as software developers (3 persons), usability engineers (3), designers (5), QA specialists (2), marketing (3) or HR (1) specialists and managers (4). The prior knowledge about DfA issues was reported as "very low" by 2 students, "low" by 3, "moderate" by 8 , "high" by 3 respondents and "excellent" by none.

Figure 2 below illustrates the distribution of responses to five Likert-style items from EQ tool, demonstrating the relatively high level of general empathy among respondents. As we did not assess the level of empathy before the course with the 
same instrument, we cannot attribute such high values of the EQ items to the course design. All five items (No. 4 is mirrored) show similar distribution of values, which indicates high reliability of EQ tool even on the level of a subset of its items.

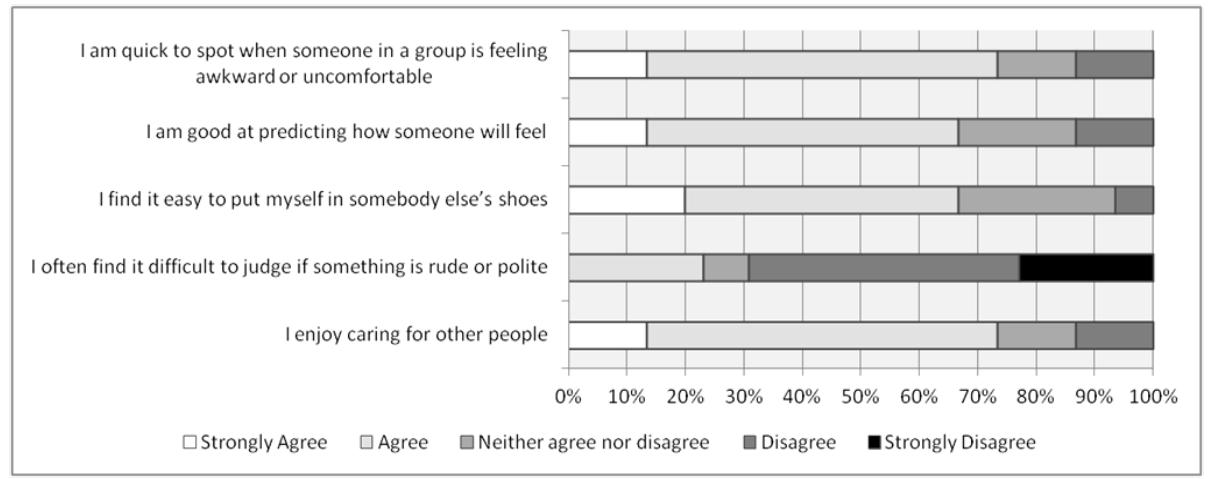

Fig. 2. Distribution of responses to generic EQ items

Figure 3 illustrates the distribution of responses to five Likert-style items that addressed the attitudes towards empathic modeling as the foundation of our course design. Almost half of the students agreed that the course increased their empathy towards users with disabilities, majority (13 out of 16) thinks the empathic modeling in physical settings helps HCI designers to understand better the DfA also in the digital context and considers it important to include such exercises in HCI study programme. There were no respondents who did not like to play the role of disabled person during the exercise, although three students remained hesitated. The general inference that can be drawn from these responses confirms that students were highly satisfied with the pedagogic design of the DfA course based on empathic modeling.

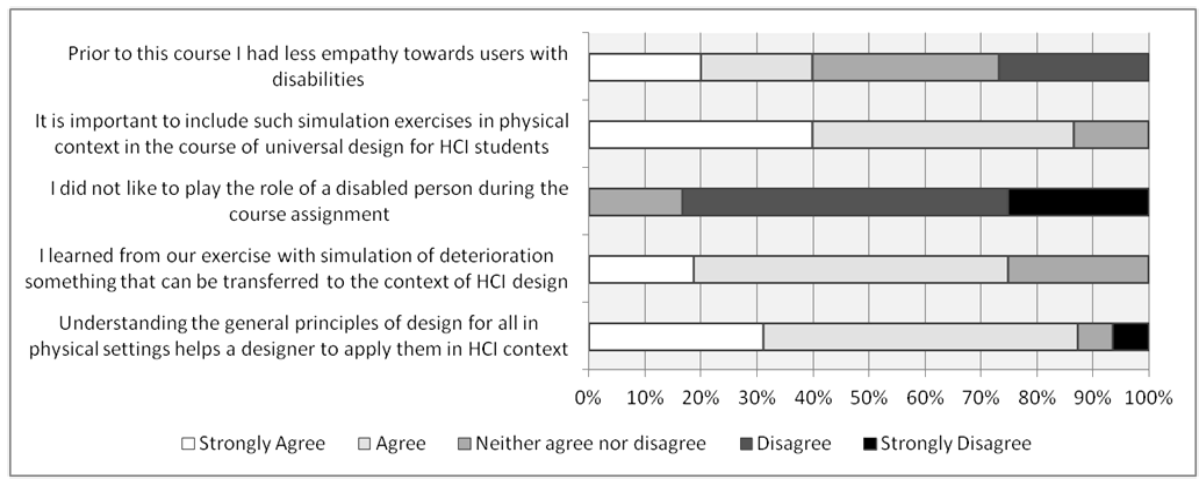

Fig. 3. Feedback from students to the course design based on empathic modeling 
When analyzing the open-ended reflections made by students after the course, there are clear indications of students' understanding of DfA issues in line with empathic modeling approach. Several students expressed highly positive attitudes towards empathic modeling exercise:

"For me this exercise was very useful and engaging. I could never imagine how really hard it can be for a person that is limited in motion to get from point A to B in our university. After walking around the university I really understood how necessary it is to communicate to people, while designing for them and to test the creations with them in order to make the design actually usable. Apparently, this principle is fair for every design field, including HCI".

"This exercise was a new experience for me, because I have never put myself in the position of an old or disabled person before and have not thought of all the possible constraints and obstacles that they may meet on their way".

Students who had already previous experience with empathic approaches to design showed more restrained reaction. However, being less enthused about empathic modeling as such, they were able to recognize the professional advantages of such exercise:

" This exercise was a not new experience for me, because I am working in youth centre about 10 years and often we have children and youth with different disabilities. But from another side, it was a new task for me think from the design part about it. I have never put attention on it in my centre or at university. After the task, I started to recognize difficulties for disabled people and what we are able to change".

And almost all students acknowledged that the exercise was a good way for understanding DfA concepts: "Definitely useful in terms of better understanding what exactly is DfA".

By answering to the second question related to finding artifacts in outside world the students showed good understanding of DfA issues:

"For me the main and most precious (meaning I will definitely use this in future work, so it's a passive contribution to my qualification) was the realization of a simple fact that "good design" is not design well serving special needs of special people, but serving equally to everybody, without making distinction or exceptions".

By discovering outside world from the new point of view some students concluded:

" Media are every day full of information about new project for people with disabilities. But when I look around in city, especially in city center, I did not see any super or obvious stuff for those people"

Several students mentioned that they didn't pay attention to lack of accessibility artifacts before.

Some students showed good understanding of interrelation between DfA and usercentered design: 
"When analyzing HCI examples I can't stop thinking of user-centered design as the primary criteria of assessment. Essentially it is about the same things in the real life defined by Don Norman: the affordances must be clear, there must be clear indication of the state of the system, the error messages must be understandable and the feedback must be relevant, etc".

By answering the last question students demonstrated good understanding of commons and differences between the physical objects in environmental context and HCI artifacts:

"...in digital environments, I think, the focus is shifted towards improving visual and logical representations, rather than appealing to physical capabilities. However, when designing for any of those fields, it is always nice to remember that very various types of people are going to use it, so no matter if we design a pen or a digital payment systems, it should be adopted for different physical and mental capabilities".

"Although physical and virtual objects obviously have different aspects, one thing in common is that both of them must be accessible for all users, but very often they lack this inclusivity. The main distinction between those two types is in different demands of user capabilities. While physical objects rely more on Ergonomic factors and in most cases require Reach \& Stretch, Dexterity and Locomotion, virtual objects do not depend on them and are mostly concentrated on Cognition, demanding more Thinking and Communication. However, Perception is important for both, as Vision and Hearing are essential, and both physical and virtual objects should be designed with vision and/or hearing impaired users in mind".

These open-ended responses demonstrate that students have mastered the core vocabulary and value basis of DfA, they are able to apply them in building their argumentation and assessment. Based on our experience from this experimental course, we believe that the students' capability of transferring the knowledge, vocabulary, skills and values of the DfA domain from physical settings to digital realm increases the likelihood of transferring academic knowledge to the world of work.

Based on the quantitative and qualitative analysis of the feedback from students, we can conclude that implementation of empathic modeling as the pedagogical approach for designing a DfA course demonstrated good results and can be recommended for teaching DfA course in HCI curriculum as a starting point for understanding principles of Design for All.

\section{References}

1. European Commission: Digital Agenda for Europe - European Commission, http:// ec.europa.eu/digital-agenda/en/our-goals/pillar-vienhancing-digital-literacy-skills-and-inclusion

2. Aegean, J.D., Rsehf, N.L.U., Romero, R., Engelen, J., Kulrd, S., Carlos, A., Verelst, T., Verbrugge, N., Miesenberger, K.: Teaching DfA Core Knowledge and Skill Sets: Experiences in including inclusive design (2004)

3. Campus, T.P., Road, B., Whitney, G., Keith, S.: Utilising Best Practice in ICT Design for All Teaching, pp. 1-18 (2008) 
4. Bohman, P.R.: Teaching Accessibility and Design-For-All in the Information and Communication Technology Curriculum: Three Case Studies of Universities in the United States, England, and Austria (2012)

5. Burzagli, L., Emiliani, P.L., Gabbanini, F.: Design for All in action: An example of analysis and implementation. Expert Syst. Appl. 36, 985-994 (2009)

6. Livi-Bacci, M.: A concise history of world population. John Wiley \& Sons, Ltd. (2012)

7. Haux, R., Howe, J., Marschollek, M., Plischke, M., Wolf, K.-H.: Health-enabling technologies for pervasive health care: on services and ICT architecture paradigms. Informatics Heal. Soc. Care 33, 77-89 (2008)

8. Zhavoronkov, A., Litovchenko, M.: Biomedical progress rates as new parameters for models of economic growth in developed countries. Int. J. Environ. Res. Public Health 10, 5936-5952 (2013)

9. Costa, R., Carneiro, D., Novais, P., Lima, L., Machado, J., Marques, A., Neves, J.: Ambient Assisted Living. In: 3rd Symposium of Ubiquitous Computing and Ambient Intelligence, pp. 86-94. Springer (2008)

10. De Ruyter, B., Zwartkruis-Pelgrim, E., Aarts, E.: Ambient Assisted Living Research in the CareLab. GeroPsych J. Gerontopsychology Geriatr. Psychiatry 23, 115-119 (2010)

11. Ambient Assisted Living, http://www. fraunhofer.pt/en/fraunhofer_ aicos/research_areas/activity_areas/aal.html

12. Emiliani, P.L., Stephanidis, C.: From Adaptations to User Interfaces for All. In: 6th ERCIM Workshop CNR-IROE, Florence, Italy (2000)

13. Newell, A.F., Gregor, P.: "User Sensitive Inclusive Design" - in search of a new paradigm. In: Proceedings on the 2000 Conference on Universal Usability, pp. 39-44. ACM (2000)

14. Edwards, A.D.N.: Extra-ordinary human-computer interaction: interfaces for users with disabilities. CUP Archive (1995)

15. Kouprie, M., Visser, F.: A framework for empathy in design: stepping into and out of the user's life. J. Eng. Des. (2009)

16. Decety, J., Jackson, P.: The functional architecture of human empathy. Behav. Cogn. Neurosci. (2004)

17. Reik, T.: Character analysis. Farrar, Strauss, Giroux, New York (1949)

18. Torrens, G.E.: Universal Design: Empathy and Affinity. In: Waldemar, K., Marcelo, M.S., Neville, A.S. (eds.) Human Factors and Ergonomics in Consumer Product Design. Methods and Techniques, pp. 233-248. Taylor \& Francis Group, Boca Raton (2011)

19. Nicolle, C., Maguire, M.: Empathic Modelling in Teaching Design for All Empathic Modelling. Univers. Access HCI Incl. Des. Inf. Soc. 4, 143-147 (2003)

20. Joy, G.-D., Waller, S.D., John, C.P.: Simulating impairment. In: Proceedings of (re) Actor3, the Third International Conference on Digital Live Art, Liverpool, pp. 3-4 (2008)

21. Center for Universal Design: Universal Design Principles, http://www. ncsu.edu/ ncsu/design/cud/about_ud/udprinciples.htm

22. Erlandson, R.F.: Universal and accessible design for products, services, and processes. CRC Press (2010)

23. Lawrence, E.J., Shaw, P., Baker, D., Baron-Cohen, S., David, A.S.: Measuring empathy: reliability and validity of the Empathy Quotient. Psychol. Med. 34, 911-924 (2004)

24. Lietz, C., Gerdes, K., Sun, F., Mullins Geiger, J., Wagaman, M.A., Segal, E.: The Empathy Assessment Index (EAI): A Confirmatory Factor Analysis of a Multidimensional Model of Empathy. J. Soc. Social Work Res. 2, 104-124 (2011)

25. Jolliffe, D., Farrington, D.P.: Development and validation of the Basic Empathy Scale. J. Adolesc. 29, 589-611 (2006) 